\title{
The Potential of Vitamin D3 to Repaired Mucosal Injury in Dextran Sulfate Sodium Induced Acute Colitis in Mice
}

\author{
Satrio Wibowo ${ }^{1 *}$, Krisni Subandiyah ${ }^{1}$, Kusworini Handono ${ }^{2}$, Sri Poeranto ${ }^{3}$ \\ ${ }^{1}$ Department of Pediatrics, Faculty of Medicine, University of Brawijaya, Malang, Indonesia; ${ }^{2}$ Department of Clinical Pathology, \\ Faculty of Medicine, University of Brawijaya, Malang, Indonesia; ${ }^{3}$ Department of Parasitology, Faculty of Medicine, University \\ of Brawijaya, Malang, Indonesia
}

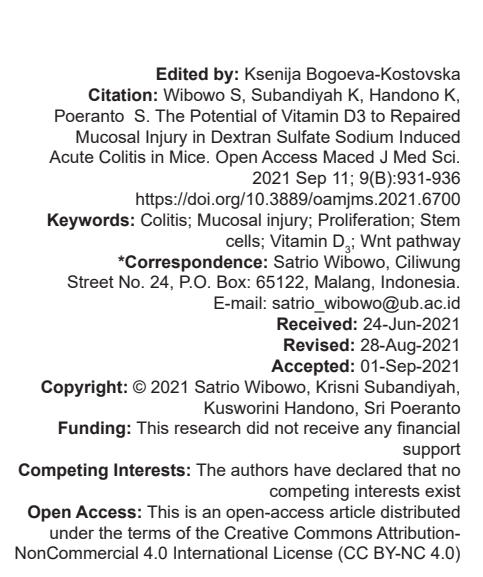

\section{Introduction}

The etiology of inflammatory bowel disease (IBD) is not yet fully understood, but some studies have revealed its potential cause to interact with multiple factors, such as infection, immunological disturbances, genetic alterations, and environment. Patients with IBD have to be hospitalized because of repeated episodes of inflammation, endoscopically mucosal injury, and microscopic ulceration of the colon, resulting in complications even have to undergo surgery [1], [2]. In histopathological assessment cryptitis and crypt abscess usually causing destructive damage of the epithelium, along with infiltration of neutrophils in lamina propria as evidence of inflammation. Recent studies have shown that in patients with IBD, the mucosal injury likely followed by an abnormal immune response. Temporarily, mucosal healing was associated for the improvement in IBD treated patients with decreased need for future corticosteroid treatment [3], [4]. Current proven therapies for achieving mucosal healing include anti-TNF $\alpha$, salicylic agents, and steroids. Another new therapeutic approach was using mesenchymal stem cells (MSCs) and hematopoietic stem cells to reconstruct the epithelial barrier in IBD. Stem cell activation to achieve mucosal healing could be performed by transplantation or transfusion but also triggered by several micro-environmental factors, such as inflammation and nutritional cues, including Vitamin D3 [5], [6], [7].

Several strands of evidence support that Vitamin $D_{3}$ has a role in maintaining the integrity of the intestinal barrier and immune homeostasis. Vitamin $D_{3}$ regulates many cell types by controlling hundreds of genes in a tissue and cell. The previous studies have underlined the potential effects of Vitamin $D_{3}$ as an inducer in the differentiation of normal colon epithelial cells and through maintaining the morphology typical of the differentiated epithelial phenotype [4], [8], [9]. Administration of Vitamin $\mathrm{D}_{3}$ is also thought to activate the Wnt canonical pathway, which could control the proliferation and differentiation of intestinal stem cells (ISC). Wnt pathways rarely investigated in inflammatory colonic tissues. It could be said that the proliferative act by ISC could cover the injury, forming channel-like structure and migrate over. Furthermore, one of the $\beta$-catenin gene products, Lgr5+, is a receptor on the cell surface that maintains intestinal epithelial homeostasis and tissue integrity. It could be used as a marker for intestinal epithelium renewal after injury. The signaling activity of stem cells will then continue in the proliferation process 


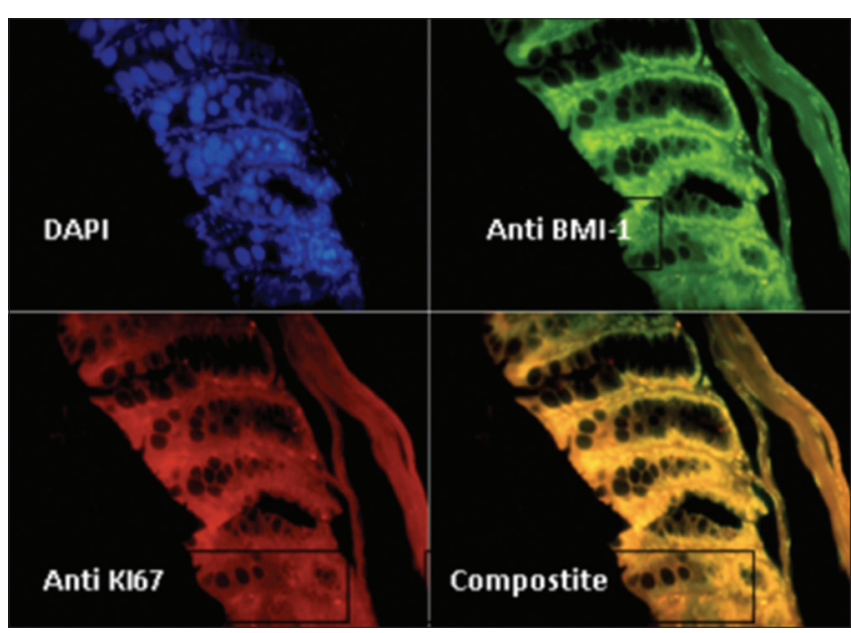

Figure 1: Immunohistochemistry/Immunofluorescence analysis

marked by an increase in Ki-67. Immunofluorescence analysis showed that $\mathrm{Ki}-67$ is widely used as a cell proliferation marker but also highly sensitive to injuries such as IBD [10], [11], [12], [13]. Based on the facts mentioned above, it is necessary to conduct a study regarding the role of Vitamin $D_{3}$ in activating, initiating proliferation which will eventually carry out renewal in repairing damaged gastrointestinal mucosal epithelium naturally.

\section{Materials and Methods}

\section{Animal studies}

Colitis induced by administration of DSS (dextran sodium sulfate; 36,000-50,000 MW; Sigma) drinking water. The DSS used in this study was purchased from MP Biomedical ${ }^{\mathrm{TM}}$ (Surabaya, Indonesia). Male C57BL/6 mice of 8 weeks randomly categorized into five groups, either received regular drinking water (control) (C- group); 5\% DSS drinking water ad libitum (w/v) for 7 days (colitis) (C+ group); and the other three groups after colitis induction with 5\% DSS then were administered Vitamin $D_{3}$ in different dosages. The dosages included $0.2 \mu \mathrm{g}$ (VD1), $0.4 \mu \mathrm{g}$ (VD2), and $0.6 \mu \mathrm{g}$ (VD3), respectively, per $25.0 \mathrm{~g} /$ day for 7 days. A total of 30 mice were randomly assigned to the control, colitis, and Vitamin $D_{3}$ treated group (each group = 5).

\section{Ethics statement}

The Ethical Commission of Health Research at the Faculty of Medicine, University of Brawijaya Indonesia, has evaluated and approved the protocol for mice use. Approval ID: no.279/EC/KEPK-S3/10/2019.

\section{Evaluation of disease activity index (DAI)}

The combined score of DAI includes weight loss, stool consistency, and occult/gross blood in the stool. Weight loss was measured on day 2 (in percentage). Stool consistency scored as well-formed scored 0 , pasty and semiformed stools scored 2 , and liquid stools scored 4 . Occult bleeding counted as 0 points for no blood, 2 points for hemoccult positive, and 4 points for gross bleeding. All scores are added up then divided by three according to the number of assessment subjects [14].

\section{Colitis histopathology score}

After being euthanized, this study used colon length as a marker of inflammation. The proximal colon was then fixated in $10 \%$ formalin and embedded in paraffin; slide 4 um-thickness sections were stained with hematoxylin and eosin $(\mathrm{H}$ and $\mathrm{E})$. Pathological changes were evaluated using the colitis histology index, which consists of four parameters (Table 1) [15].

Table 1: Mouse colitis histology index for the mouse model of colitis

\begin{tabular}{llll}
\hline Histological type & Score & & Factor \\
\hline Goblet cell loss & 0 & None & 1 \\
& 1 & $<10 \%$ & \\
& 2 & $10-50 \%$ & \\
Crypt density & 3 & $>50 \%$ & 2 \\
& 0 & Normal & \\
Crypt hyperplasia & 1 & $<10 \%$ crypt density & 2 \\
& 2 & $>10 \%$ crypt density & \\
Submucosal & 0 & None & 3 \\
infiltration & 1 & Crypt length increase <2 times & \\
& 2 & Crypt length increase 2-3 times & \\
& 3 & Crypt length increase $>3$ times & \\
& 0 & None & \\
\hline
\end{tabular}

\section{Immunohistochemistry/ Immunofluorescence analysis}

Samples of colon epithelial tissue were sliced at $4 \mu \mathrm{m}$ thickness and immunofluorescence stained to identify (1) colon cells, (2) colon stem cells, (3) activated colon stem cells, and (4) proliferating colon stem cells. 4',6-Diamidino-2-phenylindole fluorescent staining was used to determine the number of nuclei and assess gross colon cell morphology. The expression of Hes-1 is the number of IEC identified by the Hes-1 antibody (sc-166410) visualized with alexa fluor 790 , which appears as a red glow and observed by inverted olympus IX71 microscope examination with 40x magnification in five fields of view. Fluorescent Lgr5+ antibody sc-517661 (Santa Cruz Biotechnology, Inc.) was used to identify activated colon stem cells, and fluorescent basic Ki67 antibody sc-23900 (Santa Cruz Biotechnology, Inc.) was used to identify proliferating stem cells. Double immunofluorescence staining was performed using monoclonal rabbit SMAD3-rhodamine and a double-staining blocking kit (anti-Stro-1-FITC), shown in Figure 1. The sample was examined using FluoView FV-1000 (v.1.7; Olympus) by laser scanning confocal microscopy. 


\section{Statistical analysis}

Data were analyzed with SPSS 13.0 and expressed as mean \pm standard deviation (SD). The comparison of mean variability was conducted by one-way ANOVA analysis. Kruskal-Wallis and Mann-Whitney post hoc were applied to compare differences among the groups carried out for nonparametric data. Statistical significance was stated at $p<0.05$.

\section{Results}

\section{Differential dose of Vitamin D3 in ameliorated inflammation}

Mice in the colitis group $(\mathrm{C}+)$ had significantly lower colon length as a marker of inflammation than those in the Vitamin $\mathrm{D}_{3}$-treated group at $0.4 \mu \mathrm{g}$ (VD2) and $0.6 \mu \mathrm{g}$ (VD3) dose, respectively, $(10.14 \pm 0.38 ; 9.66 \pm 0.16$ vs. $8.02 \pm 0.54, p<0.01)$ (Figure 2c). As in the DAl score, DSS caused hematochezia, weight loss leading to erosions and ulcerations due to the gut inflammation process. We observed that mice induced by DSS had significantly more significant weight loss than that in the control group (C-) from day 3 to day 8 , for example, the highest DAI at VD2 and VD3 group $(8.00 \pm 0.24 ; 7.33$ $\pm 0.26, p<0.01)$. However, mice in the Vitamin $D_{3}$ group, even in a small dose (VD1), had rapid weight recovery from day 9 to day 14 . We found that only the group with middle (VD2) and high dose (VD3) of Vitamin $D_{3}$ has DAl scores lowered significantly than those in the colitis group $(\mathrm{C}+)(1.50 \pm 1.19$; $1.75 \pm 0.25$ vs. $6.00 \pm 1.41, p<0.05)$. Other than

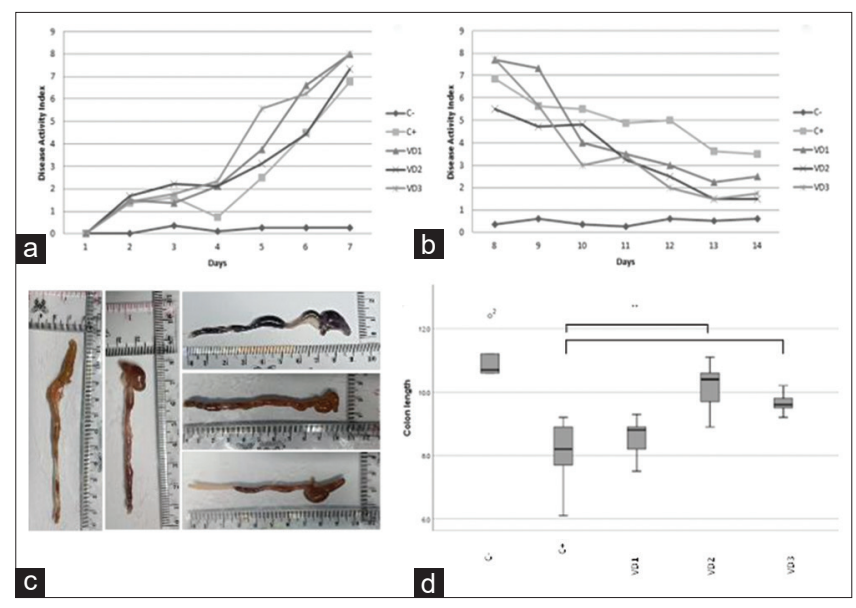

Figure 2: (a) The DAl score increased in mice treated with DSS compared to the untreated control group ${ }^{*} p<0.05$ compared at day 1-day 7. (b) The DAl scores decreased in the groups given various doses of Vitamin $D_{3}$ for 7 days after DSS induction. $n=5$; \#p<0.05 at day 8-day 14. (c) Colon length measured and a representative of each group. (d) Box plot of colon length showed VD2 and VD3 significant $(p<0.05)$ vs. colitis group. that, the group with lower doses of Vitamin $D_{3}(V D 1)$ did not significantly lower the DAI score (Figure 2a and $b$ ).

Histological analysis showed that $5 \%$ DSSinduced colitis group $(\mathrm{C}+)$ showed extensive ulceration of the epithelial layer, infiltration of inflammatory cells, and crypt damage of colon wall. It is also proved mucosal injury in mice induced with 5\% DSS. For example, the inflammation process was proved by the presence of neutrophils infiltrating crypt epithelium compared to the control group (C-) (Figure 3b). This study showed that the histology score in the colitis $(\mathrm{C}+)$ group had significantly higher than that in control (C-) group $(20.30 \pm 0.64$ vs. $2.38 \pm 0.98, p<0.01)$. Nevertheless, mice in the Vitamin $D_{3}$ group have compromising to reduce colitis histology index by starting from a low dose, the observation of fewer neutrophils infiltration and cryptitis progresses toward spontaneous healing as the dose of Vitamin $D_{3}$ increased. However, mucosal healing has not been seen optimally in the presence of inflammatory cells and ulceration, implying the damage to colon tissues was not completely repaired. The colitis histology index of the VD2 and VD3 groups is significant $(p<0.01)$ lower than the colitis group, indicating the possibility of good therapeutic effect Vitamin $D_{3}$ in dose $0.4-0.6 \mu \mathrm{g} / 25.0 \mathrm{~g} /$ day.

\section{Differential dose of Vitamin $D_{3}$ regenerating intestinal mucosal epithelium}

To determine whether administration of Vitamin $\mathrm{D}_{3}$ could promote proliferation and differentiation of colonic epithelial cells into processed healing injury in colitis, the expression of Ki67 (one of the markers

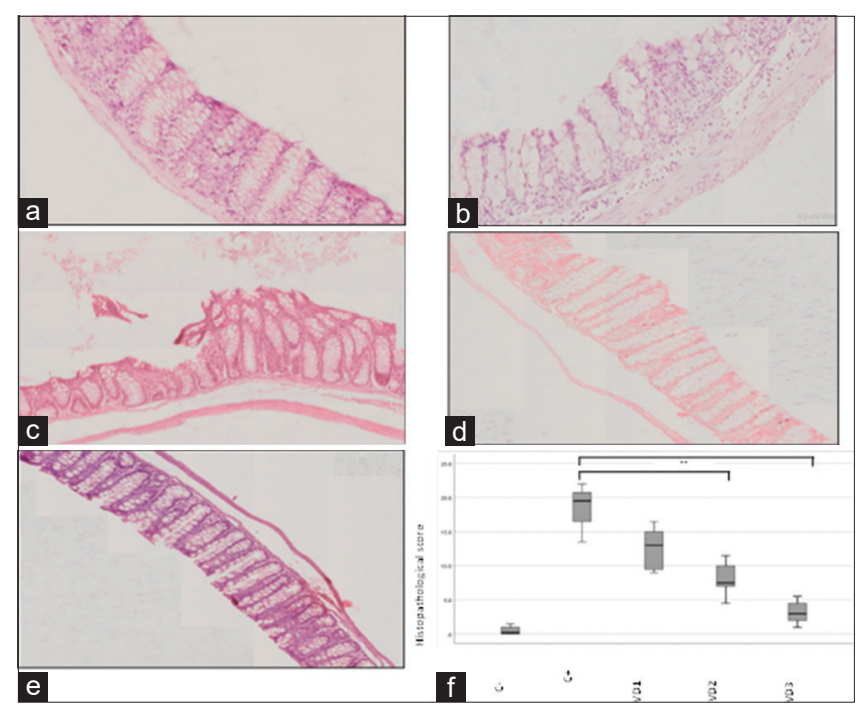

Figure 3: Histopathological images of the colon epithelium from a mouse model of colitis. (Hematoxylin and eosin staining with a magnification of $400 \times$, bar $=50 \mu \mathrm{m})$. (a) Controls group (C-), (b) Colitis group (C+), (c) DSS colitis treated with low dose Vitamin $D_{3}(V D 1)$, (d) medium-dose Vitamin $D_{3}(V D 2)$, (e) high dose Vitamin $D_{3}$ (VD3) (f). Comparisons of histopathological scores. Values are expressed as mean $\pm S D$. ${ }^{* *} p<0.05$. 
of cell proliferation) and Lgr5 (one of the markers of differentiation cells crypt base columnar) was examined by immunohistochemistry. Seven days after treated with Vitamin $D_{3}$, the expression of Ki67 and Lgr5+ in the VD2 and VD3 group increased significantly compared with colitis group $(\mathrm{C}+)(\mathrm{Ki} 67: 277.00 \pm 24.32$ vs. $162.75 \pm 8.68$, p < 0.05; Lgr5: $206.25 \pm 7.92 \times 103$ vs. $150.75 \pm 11.49$ $\times 103, p<0.05)$. Immunofluorescence staining revealed that Lgr5+ expression relatively strong fluorescence intensity and abundant in the basal colonic epithelium. The immunofluorescence analyses showed that leucinerich repeat-containing G-protein coupled receptor 5 (Lgr5) were enriched at the bottom of crypts, meanwhile Ki67 shows at the side of crypt colon (Figure 4). We could also note that in control group (C-), these two protein expressions were quite high compared to the colitis group $(\mathrm{C}+)$, which defines that colitis disrupts the regulation of body homeostasis to heal injured tissues. These data suggested that Vitamin $D_{3}$ may accelerate crypt epithelial cell proliferation and differentiation to promote mucosal healing by the absence of ulceration.

\section{Discussion}

ISC are a source of rapid renewal of the intestinal epithelium and beneficial for diseases with the pathophysiology of tissue damage or need to be replaced. ISC showed proliferation and differentiation activity and were able to restore the intestinal mucosa through Wnt signaling pathway. The Wnt signaling cascade is a key pathway that regulates stem cell homeostasis, inhibition of cell differentiation, and control of Paneth cell development. The Canonical signaling activated by Wnt3a enhances the proliferation of MSCs and previous study found that the expression escalate in IBD colon tissues [16], [17].

Evidence from clinical activities, histopathological and immunofluorescence analysis suggest that Vitamin $D$ may be beneficial against colitis to achieved mucosal healing. In our study, we established that Vitamin $D_{3}$ prompted Wnt canonical signaling through Vitamin $D$ receptors (VDR). Leucine rich repeat containing $G$ protein-coupled receptor 5 (Lgr5) is an adult stem cell marker in multiple tissues including intestinal epithelium. Lgr5 could regulate the invasion, migration of colonic cells [18], [19]. Examination of Lgr5+ expression in the DSS-treated mice by immunofluorescence staining showed a proportional increase in expression with the increasing dose of Vitamin $D_{3}$, meanwhile also appeared in the control group. In agreement with the previous studies that stated VDR expressed in Lgr5 colon stem cells in human tissue in normal conditions [20]. Temporarily, Ki-67 indicate cell proliferation and differentiation marker and found significantly increased in the previous study compared to non-colitis mice [21]. While the analysis also identified the proliferation index Ki67 was found to slightly decreased in colonic epithelial crypts from damaged mucosa. Mice treated with
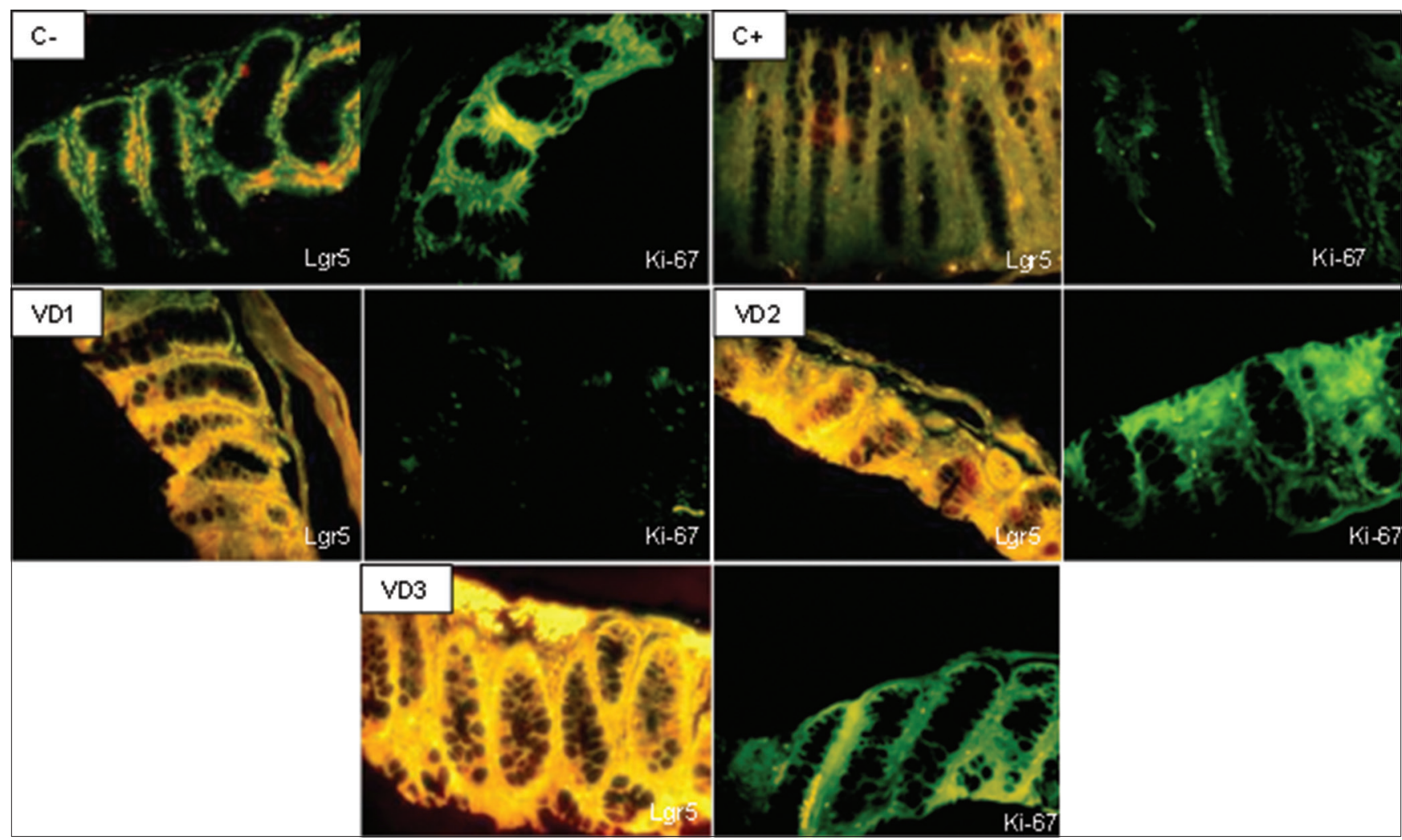

Figure 4: Immunofluorescence staining for stem cells. 
Vitamin $D_{3}$ had successfully induced mucosal healing by extension of protein $\mathrm{Ki}-67$ in mucosal colon lining. The lower serum Vitamin $D_{3}$ levels by colitis condition were in turn implicated in the rapid inactivation of VDR expression in Lgr5+ cells or Ki-67 and a subsequent loss of stem cell function. Therefore, low Vitamin $D_{3}$ exposure was considered similar to the stress induced by radiation and chemically induced inflammation, implicating Vitamin $D_{3}$ as an extrinsic variable that determines the function of Lgr5+ and $\mathrm{Ki}-67$ in colon stem cells [17], [21], [22], [23]. However, there are limitations to knowing that IHC/IF does not have precise accuracy for counting proteins, and it would be better to use Western Blot or ELISA. Apart from that, research to detect stem cells in the colon, especially for IBD, is still rare, so it requires variable results from another protein expression, especially in the Wnt pathway.

Vitamin $D_{3}$ treatment also improved mucosal damage and clinical symptoms in the mouse colitis model. The $\mathrm{MCHI}$ score, which identifies the degree of mucosal damage, decreased significantly in response to Vitamin $D_{3}$ treatment, while the DAl score increased significantly, confirming that Vitamin $D_{3}$ has pleiotropic effects that go beyond its traditional role in calcium homeostasis [24], [25]. Stranded evidenced thought that Vitamin $D_{3}$ could improve intestinal brush-border caused by the inflammation process. It was increasing the proliferation of colonic mucosal cells and showed the minimal absence of erosions and ulceration in order to heal [21], [26]. The histopathological appearance at the highest dose of Vitamin $D_{3}$ had best view similar to the control group except in goblet cell and submucosal infiltration. Therefore, Vitamin $D_{3}$ could repair mucosal injury in mice with colitis but cannot restore the same histological appearance as healthy mucosa.

\section{Conclusions}

Wnt signaling pathway activation evolutionarily conserved tissue in colon, which can be transiently activated for wound repair. Vitamin $D_{3}$ could have an important role for IBD patient, as it showed significant effects on colon stem cell activation and proliferation in the mouse model of colitis. In addition, direct evidence showing that Vitamin $D_{3}$ either influences stemness maintenance or proliferation needs to be demonstrated in further studies.

\section{References}

1. Gade AK, Douthit NT, Townsley E. Medical management of Crohn's disease. Cureus. 2020;12(5):e8351. https://doi. org/10.7759/cureus.8351

PMid:32617224

2. Xu CT, Meng SY, Pan BR. Drug therapy for ulcerative colitis. World J Gastroenterol. 2004;10(16):2311-7.

PMid: 15285010

3. Gui X, Li J, Ueno A, lacucci M, Qian J, Ghosh S. Histopathological features of inflammatory bowel disease are associated with different CD4+ $T$ cell subsets in colonic mucosal lamina propria. J Crohns Colitis. 2018;12(12):1448-58. https://doi.org/10.1093/ ecco-jcc/jjy116

PMid:30137280

4. Lichtenstein GR, Rutgeerts P. Importance of mucosal healing in ulcerative colitis. Inflamm Bowel Dis. 2010;16(2):338-46. https:// doi.org/10.1002/ibd.20997

PMid:19637362

5. Dave M, Loftus EV Jr. Mucosal healing in inflammatory bowel disease-a true paradigm of success? Gastroenterol Hepatol (NY). 2012;8(1):29-38

PMid:22347830

6. Klenske E, Bojarski C, Waldner M, Rath T, Neurath MF, Atreya R. Targeting mucosal healing in Crohn's disease: What the clinician needs to know. Therap Adv Gastroenterol. 2019;12:1756. https://doi.org/10.1177/1756284819856865 PMid:31236140

7. Shimizu H, Suzuki K, Watanabe M, Okamoto R. Stem cellbased therapy for inflammatory bowel disease. Intest Res. 2019;17(3):311-6. https://doi.org/10.5217/ir.2019.00043 PMid:31352774

8. Zhao H, Zhang H, Wu H, Li H, Liu L, Guo J, et al. Protective role of $1,25(\mathrm{OH}) 2$ Vitamin D3 in the mucosal injury and epithelial barrier disruption in DSS-induced acute colitis in mice. BMC Gastroenterol. 2012;12:57. https://doi. org/10.1186/1471-230x-12-57

PMid:22647055

9. Cosín-Roger J, Ortiz-Masiá D, Calatayud S, Hernández C Alvarez A, Hinojosa J, et al. M2 macrophages activate WNT signaling pathway in epithelial cells: Relevance in ulcerative colitis. PLoS One. 2013;8(10):e78128. https://doi.org/10.1371/ journal.pone.0078128 PMid:24167598

10. Choi $Y S$, Zhang $Y, X u M$, Yang $Y$, Ito $M$, Peng $T$, et al. Distinct functions for Wnt/ $\beta$-catenin in hair follicle stem cell proliferation and survival and interfollicular epidermal homeostasis. Cell Stem Cell. 2013;13(6):720-33. https://doi.org/10.1016/j. stem.2013.10.003

PMid:24315444

11. Flanagan DJ, Austin CR, Vincan E, Phesse TJ. Wnt signalling in gastrointestinal epithelial stem cells. Genes (Basel). 2018;9(4):178. https://doi.org/10.3390/genes9040178 PMid:29570681

12. Carmon KS, Gong X, Yi J, Wu L, Thomas A, Moore CM, et al LGR5 receptor promotes cell-cell adhesion in stem cells and colon cancer cells via the IQGAP1-Rac1 pathway. J Biol Chem. 2017;292(36):14989-5001. https://doi.org/10.1074/jbc. m117.786798 PMid:28739799

13. Cidado J, Wong HY, Rosen DM, Cimino-Mathews A, Garay JP, Fessler AG, et al. Ki-67 is required for maintenance of cancer stem cells but not cell proliferation. Oncotarget. 2016;7(5):6281-93.

PMid:26823390

14. Murthy SN, Cooper HS, Shim H, Shah RS, Ibrahim SA, Sedergran DJ. Treatment of dextran sulfate sodium-induced murine colitis by intracolonic cyclosporin. Dig Dis Sci. 
1993;38(9):1722-34. https://doi.org/10.1007/bf01303184 PMid:8359087

15. Kitajima S, Takuma S, Morimoto M. Histological analysis of murine colitis induced by dextran sulfate sodium of different molecular weights. Exp Anim. 2000;49(1):9-15. https://doi. org/10.1538/expanim.49.9 PMid:10803356

16. Abreu-Delgado $\mathrm{Y}$, Isidro RA, Torres EA, González A, Cruz ML, Isidro $A A$, et al. Serum Vitamin $D$ and colonic Vitamin $D$ receptor in inflammatory bowel disease. World J Gastroenterol. 2016;22(13):3581-91. https://doi.org/10.3748/wjg.v22.i13.3581 PMid:27053850

17. Komiya $\mathrm{Y}$, Habas R. Wnt signal transduction pathways. Organogenesis. 2008;4(2):68-75. https://doi.org/10.4161/ org.4.2.5851

PMid: 19279717

18. Peregrina K, Houston M, Daroqui C, Dhima E, Dhima E, Sellers RS, Augenlicht LH. Vitamin D is a determinant of mouse intestinal Lgr5 stem cell functions. Carcinogenesis. 2015;36(1):25-31. https://doi.org/10.1093/carcin/bgu221 PMid:25344836

19. Huang J, Chen T, Liu Y, Lyu L, Li X, Yue W. How would serum 25 $(\mathrm{OH}) \mathrm{D}$ level change in patients with inflammatory bowel disease depending on intestinal mucosa Vitamin $D$ receptor (VDR) and Vitamin D1- $\alpha$ hydroxylase (CYP27B1)? Turk J Gastroenterol. 2019;30(2):132-8. https://doi.org/10.5152/tjg.2018.17828 PMid:30429108

20. Fernández-Barral $A$, Costales-Carrera $A$, Buira $S P$, Jung $P$, Ferrer-Mayorga G, Larriba MJ, et al. Vitamin D differentially regulates colon stem cells in patient-derived normal and tumor organoids. FEBS J. 2020;287(1):53-72. https://doi.org/10.1111/ febs.14998
PMid:31306552

21. Garcia PM, Moore J, Kahan D, Hong MY. Effects of Vitamin D supplementation on inflammation, colonic cell kinetics, and microbiota in colitis: A review. Molecules. 2020;25(10):2300. https://doi.org/10.3390/molecules25102300

PMid:32422882

22. Pike JW, Meyer MB. The Vitamin D receptor: New paradigms for the regulation of gene expression by 1,25-dihydroxyvitamin D(3). Endocrinol Metab Clin North Am. 2010;39(2):255-69.

\section{PMid:20511050}

23. Bouillon R, Carmeliet G, Verlinden L, van Etten E, Verstuyf $A$, Luderer HF, et al. Vitamin D and human health: Lessons from Vitamin D receptor null mice. Endocr Rev. 2008;29(6):726-76. https://doi.org/10.1210/er.2008-0004

PMid: 18694980

24. Bradford EM, Ryu SH, Singh AP, Lee G, Goretsky T, Sinh P, et al Epithelial TNF receptor signaling promotes mucosal repair in inflammatory bowel disease. J Immunol. 2017;199(5):1886- 97. https://doi.org/10.4049/jimmunol.1601066

PMid:28747340

25. Ardesia M, Ferlazzo G, Fries W. Vitamin D and inflammatory bowel disease. Biomed Res Int. 2015;2015:470805. https://doi. org/10.1155/2015/470805

PMid:26000293

26. Chen $\mathrm{QQ}$, Yan $\mathrm{L}$, Wang $\mathrm{CZ}$, Wang $\mathrm{WH}$, Shi $\mathrm{H}$, Su BB, et al Mesenchymal stem cells alleviate TNBS-induced colitis by modulating inflammatory and autoimmune responses. World J Gastroenterol. 2013;19(29):4702-17. https://doi.org/10.3748/ wjg.v19.i29.4702

PMid:23922467

Author Queries???

AQ1: Kindly provide history details 